\title{
From individual resource to social capital: The mechanism of how political skill affect job satisfaction and turnover intention
}

\author{
Yi Li ${ }^{1}$, Mengqiu Ma ${ }^{2, *}$ \\ 1 School of management, Shanghai University,Shanghai 200444,China; liyi@t.shu.edu.cn(Y.L.); \\ 2 School of management, Shanghai University,Shanghai 200444,China; maggiexxxq@163.com(M.M.) \\ * Correspondence: maggiexxxq@163.com; Tel.: +86-187-2101-2798
}

\begin{abstract}
From the perspective of individual resource and social capital, this paper aims to explain how employees' political skill affect their job satisfaction and turnover intention, through the mediating role of popularity. Using a sample of 237 dyad surveys from supervisors and employees in the Yangtze River Delta of China, we found that: 1) political skill is positively correlated with job satisfaction and negatively correlated with turnover intention, and that these correlations are partially mediated by individual popularity; 2) positive affect (PA) moderates the relationship between political skill and job satisfaction, and negative affect (NA) moderates the relationship between political skill and turnover intention. The implications of our findings and future research directions are discussed.
\end{abstract}

Keywords: political skill; job satisfaction; turnover intention; popularity; positive affect; negative affect.

\section{Introduction}

Employees' job satisfaction and turnover intention has been the major subject in organizational behavior for decades, and scholars have never stopped exploring their antecedents 1 . It has been identified that situational factors and personal traits could predict employees' job satisfaction and turnover intention (e.g. the "Big Five", proactive personality, job performance, leadership style, organizational culture, perceived organizational support, person-organization fit)5. However, few studies examined how individual resource affect job satisfaction and turnover intention from a perspective of resource.

According to Hobfoll's9 definition of personal resources (e.g. key skills and personal traits), political skill, referring to "the ability to effectively understand others at work, and to use such knowledge to influence others to act in ways that enhance one's personal and/or organizational objectives" 10( p. 127), is definitely a kind of crucial resource of an individual. Yet much of the extant literature has mainly examined either the direct effect or the moderating effect of political skill on task performance, career success and personal attitudes and behaviors such as trust, job satisfaction, turnover intention, organizational commitment and organizational citizenship behavior (OCB)11, with little demonstrating the internal mechanisms and boundary conditions of the relationships17. One goal of our study, thus, is to clarify the complicated mechanisms underlying the relationship between political skill and employees' job satisfaction and turnover attention through the lens of resource transformation.

The current research attempts to explore how politically skilled employees manage to realizing the transformation from individual resource to social capital and in turn increases job satisfaction 
and decreases turnover intention. Given that social capital can be developed through political skill and arises from the politically skilled individual's acceptance by their coworkers (i.e. their popularity)18,19, we propose that popularity, as a mediator, plays an important role in liking employee's political skill to their job satisfaction and turnover intention. And in developing our hypotheses, we further incorporate positive affect (PA) and negative affect (NA), two kinds of individual's emotional resources20, as moderators to identify the boundary conditions under which the direction and strength of the relationships between political skill and job satisfaction and turnover intention differ.

Following the path of the transformation from individual resources to social capital, our study adopt the social capital theory to provide a broader theoretical picture of the relationship between political skill and job satisfaction and turnover intention. In so doing, the present study addresses gaps in several ways. First, from a perspective of individual resource, we explore how employee's political skill affects their job satisfaction and turnover intention under conditions of high or low PA/NA. Second, our study develop a theoretical framework of how politically skilled employees manage to transform their individual resource to social capital (i.e. popularity), and sequentially strengthen job satisfaction and weaken turnover intention on the basis of social capital theory21. Third, we extend the limited nomological network and settings of popularity by investigating its mediating role in the relationship between political skill and job satisfaction and turnover intention, which related to workplace.

A model depicting our theoretical framework is presented in Figure 1.

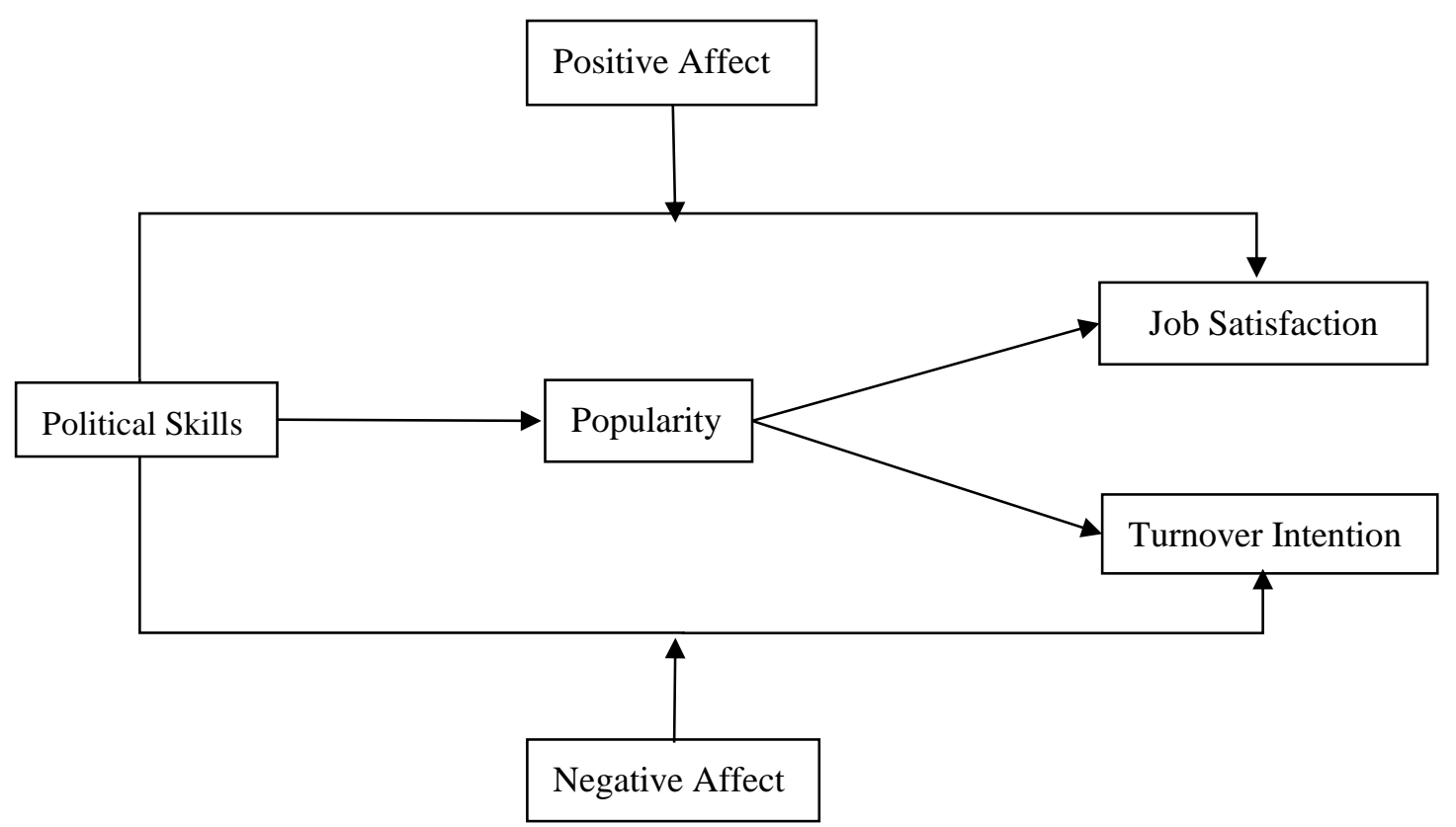

Figure 1. The conceptual model of the study

\section{Theoretical Background and Hypotheses}

\subsection{Theoretical background}

Pfeffer22, who was one of the first researchers to use the term political skill in the literature, argued that individuals need to exercise political skill to be successful in their organizations. Similarly, Mintzberg23 suggested that political skill is exercised through persuasion, manipulation, and negotiation. Later, Ferris et al.10(p. 127) defined political skill as "the ability to effectively understand others at work, and to use such knowledge to influence others to act in ways that enhance one's personal and/or organizational objectives". As mentioned above, Hobfoll9 defined resources as objects, personal characteristics, conditions, and other things that are valued by the 
individual or that act as a means of people's obtaining valued goals. Hence, political skill is particularly key as an individual resource.

Scholars also identified four key dimensions of the political skill construct, namely, social astuteness, interpersonal influence, networking ability, and apparent sincerity10. Social astuteness refers to the capacity of politically skilled individuals to astutely observe others and stay keenly attuned to diverse social situations. Interpersonal influence refers to the ability of politically skilled individuals to exert a powerful influence on those around them through their subtle and convincing personal style. Networking ability refers to the ability of politically skilled individuals to develop and use diverse networks of people. Finally, apparent sincerity refers to politically skilled individuals' abilities to inspire trust and confidence in and from those around them by appearing to possess high levels of integrity, authenticity, and genuineness.

A wealth of research in the fields of developmental and educational psychology has shown that popularity can substantially influence the ways in which individuals are viewed and treated by others during their school-age years24. However, far less is known about the popularity in the workplace among the organizational behavior literature. In a study based on an organizational setting, Scott and Judge18 defined popularity as "generally being accepted by one's peers."

Although popularity is a property of the focal employee, Scott and Judge (2009) noted that to gain popularity, the employee must be embedded in a group. Accordingly, popularity needs to be regarded as "both an individual and group-oriented phenomenon" 24. "Popular" and "unpopular" are labels that group members confer on a focal employee and which reflect the general opinion of "the beholders" rather than "the beholder" of the group 25. In a similar vein, Cullen, Fan and Liu26 argued that workplace popularity reflects the degree to which an individual is socially accepted by his or her coworkers. Overall, popularity can be seen to reflect the quality of the workplace relationships individuals develop with others.

From a social capital perspective, Adler27(p. 18)defines social capital as "the resource available to actors as a function of their location in the structure of their social relations", and social capital includes both the social resources embedded in the network structures and the different network structures provided access to social resources28. So popularity is absolutely a kind of social capital embedded in individual's social relationships network in the workplace, and its practice depends largely on the use of personal power and influence 26.

\subsection{Political skill, job satisfaction, and turnover intention}

Perrew et al.29 argued that political skill is a personal characteristic and that politically skilled individuals are highly astute and able to regulate their behavior to show sincerity and gain support and trust, and effectively influence and control others in relation to different situations. Accordingly, political skill can be seen to reflect dispositional characteristics such as behavioral flexibility and situational variability30, which facilitate interpersonal interaction, trust, and relationship building, and thereby provide employees with access to social capital.

As an internal resource of individuals, politically skilled individuals are highly socially astute and display strong interpersonal influence, networking abilities, and apparent sincerity, along with the belief that they can control the processes and outcomes of their interactions with others, they are more likely to have better social networking abilities, which are critical for achieving personal goals 10,16. Besides, such networking abilities enable employees to build stable friendships and strong alliances and coalitions. These relationships help the employees to obtain the external resources and leverage it to achieve their personal goals and maybe even their organizational goals. Therefore, from a resource perspective, politically skilled individuals who are competent at developing and utilizing both the internal and external resources are more adept at handling workplace relationships and achieving high performance goals, which in turn simultaneously increases their job satisfaction and decreases their turnover intention. 
Furthermore, Ferris et al.31 argued that political skill is likely to generate a sense of self-confidence because politically skilled individuals experience a greater sense of understanding and control over people at work, and are able to use the requisite tactics to get what they want. This increased confidence and sense of control and the ability to get what they want mean that politically skilled individuals experience higher levels of job satisfaction and lower turnover intention.

Therefore, based on the above discussion, we propose the following:

H1. Political skill is positively related to job satisfaction.

H2. Political skill is negatively related to turnover intention.

\subsection{The mediating effect of popularity}

According to social capital theory2128, popularity can be seen to originate from the relationships network that individuals create and maintain through their political skill. In this respect, political skill serves as an important individual resource of facilitating high quality relationships networks with coworkers. More specifically, politically skilled individuals tend to be socially astute and have the capacity to adjust their behavior to suit different workplace relationships and change the situational demands in a manner that appears to be sincere and credible, thereby inspiring support and trust. Moreover, politically skilled individuals tend to have strong networking capabilities and interpersonal influence, and thus are involved in more frequent interactions and are able to effectively influence and even control the responses of others. Hence, politically skilled individuals tend to experience high levels of popularity among their coworkers 18 .

Based on our general theoretical framework, we propose that popularity is a mechanism through which political skill affects job satisfaction and turnover intention. Because politically skilled individuals are more likely to be widely accepted by their coworkers, gain the trust of others, develop useful interpersonal networks, and get more help, they are likely to experience increased job satisfaction and decreased turnover intention. Scott19 suggested that popularity provides individuals with more access to social capital, and research suggests that the employees' popularity has a significantly positive relationship with their career satisfaction32. So it is easily to understand that popular employees tend to complete their task and fulfill their goals much more easily with those social capital, which in turn make them more satisfied with their present state and unwilling to leave their current job. Furthermore, research also indicates that popular individuals with greater amounts of social capital are more satisfied with their jobs2833. In line with this, we propose that popularity mediates the relationships between political skill and job satisfaction and turnover intention.

H3. Popularity mediates the relationship between political skill and job satisfaction.

H4. Popularity mediates the relationship between political skill and turnover intention.

\subsection{The moderating effects of $P A$ and $N A$}

Watson et al.34 proposed that affective traits are composed of two dimensions: positive affect (PA) and negative affect (NA). PA reflects the extent to which a person feels enthusiastic, active, and alert. In contrast, NA is a dimension of general subjective distress and unpleasant engagement that incorporates a variety of averse mood states, including anger, contempt, disgust, guilt, fear, and nervousness. According to Hobfoll's9 definition of resources, PA/NA can be viewed as an inherent and stable individual resource, which is helpful to explain employees' job satisfaction and turnover intention20.

The moderating effects of PA. Individuals with high PA are more optimistic, positive, and inclined to give a higher evaluation of a certain object, whereas individuals with low PA are more pessimistic, negative, and inclined to give a lower evaluation of a certain object (Watson et al., 1988). Job satisfaction, as a type of attitude, is likely to be affected by individual's emotional resource 20 . 
Hence, individuals who possess high PA tend to be positive and display strong self-efficacy regardless of the actual situation35, which keeps them from worrying about their level of political skill and position within the organization too much. In this case, political skill doesn't make much difference to individuals' job satisfaction. Conversely, a slight improvement of individual political skill significantly improves their job satisfaction for individuals with low PA. Therefore, we predict that PA will have the following moderating effect:

H5. PA moderates the relationship between political skill and job satisfaction such that the relationship is stronger for individuals with low $P A$ than for their counterparts with high PA.

The moderating effects of NA. Similarly, individuals with low NA are in a state of calmness and serenity35 and with high NA are more likely to be pessimistic, lacking in confidence, and dissatisfied with their jobs. Because politically skilled individuals are adept at networking and creating social capital10, they are likely to have many connections outside their current organization, which in turn, provide those with high NA with more opportunities and reasons to leave their positions. Therefore, we propose that individuals with high NA promote the development of their turnover intention.

Overall, individuals with high NA and who possess high levels of political skill are more likely to leave their current organization and find another position in which they can give full play to their political skill. That is, turnover intention increases as political skill improves. On the contrary, the outcomes are likely to be different for individuals with high political skill in the case of low NA. More specifically, individuals with low NA have less negative feelings about their organization, and the development of political skill is likely to decrease turnover intention. Therefore, we predict that NA will have the following moderating effect:

H6. NA moderates the relationship between political skill and turnover intention such that political skill is positively related to turnover intention for individuals with high NA and negatively related to turnover intention for individuals with low NA.

\section{Method}

\subsection{Sample and Procedure}

In the beginning, 97 supervisors and 303 employees from 4 companies located in the Yantze River Delta of China were recruited to take part in the field survey. Employees and supervisors filled out their own survey separately and each survey was given a unique identification code in order to make sure of the matching of supervisor-employee data. Finally, we got two hundred and thirty-seven dyad surveys, which were returned valid (a return rate of 59.25 percent).

Of the 40 companies we surveyed, 43 percent were in manufacturing and the remaining 57 percent were in the service sector. Approximately 58.5 percent of the respondents were male, 40.5 percent were aged 31 to 35 and 35.5 percent were aged 26 to 30.64 .5 percent of the sample had a Bachelors' degree and 28 percent a postgraduate degree. Also, 68 percent of the respondents had worked more than three years in the current organization, 71 percent had worked more than three years in the current position, 38 percent had worked more than three years with their immediate supervisor and 55.5 percent had never had a promotion in the current organization.

\subsection{Measures}

Political skills. The 18-item Political Skill Inventory (PSI) developed by Ferris et al.10 and later used by Wei et al.36 in a Chinese context was used to measure employees' political skill. A sample item from this scale is, "I am good at building relationships with movers and shakers." The responses were rated on a scale ranging from "never" (0) to "always" (5). Cronbach's alpha for the whole scale was 0.94 . 
Popularity. To obtain the data on employees' popularity as evaluated by the supervisors, we used the eight-item scale developed by Scott and Judge18. A sample item is, "The employee is widely accepted by others." The responses were rated on a scale ranging from "strongly disagree" (1) to "strongly agree" (7). The average score of responses from the supervisors was used to compute this measure. Cronbach's alpha for the scale was 0.889 .

Positive affect and negative affect. Watson's34 positive affectivity and negative affectivity scales comprise 20 items: 10 items for PA and 10 for NA. A sample item for PA is, "I often feel excited." A sample item for NA is, "I often feel depressed." The responses were rated on a scale ranging from "strongly disagree" (1) to "strongly agree" (6). Cronbach's alpha was 0.941 and 0.897 , respectively.

Job satisfaction. We used the five-item scale developed by Brayfield and Rothe1 to measure job satisfaction. A sample item is, "I am quietly satisfied with my present job." The responses were rated on a scale ranging from "strongly disagree" (1) to "strongly agree" (5). Cronbach's alpha was 0.942.

Turnover intention. To measure turnover intention, we made some modifications to the expression of the three-item scale designed by Mobley37, which in order to be suitable for the Chinese context. A sample item is, "I might leave the organization in three years." The responses were rated on a scale ranging from "strongly disagree" (1) to "strongly agree" (6). Cronbach's alpha for the modified scale was 0.814 .

To verify whether the scales fit the variables suitably and effectively, we conducted a confirmatory factor analysis (CFA) on all of the items in each scale. The analyses of the variables indicated that each of the scales was an exact match.

Control variables. Previous research have testified the effect of gender, age, tenure with immediate supervisor on employees' political skills, popularity, PA and NA13,34,3834, we thus controlled for these demographic variables. Furthermore, we controlled for educational background, total compensation, promotions in current and previous organizations, position tenure and organizational tenure because these variables may potentially influence employees' political skill, job satisfaction and turnover intention.

\subsection{Data analysis}

In our data analysis, we used correlation analysis (CA) and hierarchical multiple regression analysis. First, using SPSS, we tested the correlations of the independent variables, mediating variable, moderating variables, and dependent variables based on the Pearson CA method. Second, we conducted a hierarchical multiple regression analysis to verify the main effect of political skill, the mediating effect of popularity, and the moderating effects of PA and NA. We tested our hypotheses based on the results of these analyses.

\subsection{Results}

Table I. Means, standards deviations, correlations, and cronbach's $\alpha$ of the study variables

\begin{tabular}{lcccccccc}
\hline \multicolumn{1}{c}{ Variable } & $M$ & $S D$ & 1 & 2 & 3 & 4 & 5 & 6 \\
\hline 1.Political skills & 2.834 & 0.624 & $(0.904)$ & & & & & \\
2.Job satisfaction & 3.895 & 0.971 & $0.388^{* *}$ & $(0.942)$ & & & & \\
3.Turnover intention & 3.207 & 1.199 & $-0.154^{*}$ & $-0.322^{* *}$ & $(0.814)$ & & & \\
4.Popularity & 4.402 & 0.897 & $0.222^{* *}$ & $0.289^{* *}$ & $-0.175^{*}$ & $(0.889)$ & & \\
5.Positive affect & 4.061 & 0.899 & $0.389^{* *}$ & $0.579^{* *}$ & $-0.253^{* *}$ & $0.223^{* *}$ & $(0.941)$ & \\
6.Negative affect & 2.910 & 0.947 & -0.126 & $-0.351^{* *}$ & $0.222^{* *}$ & $-0.158^{*}$ & $-0.404^{* *}$ & $(0.897)$ \\
\hline
\end{tabular}


Notes: $n=237 . * p<0.05, * * p<0.01$.

As shown in Table I, our results show significant correlations between the independent, mediating, moderating, and dependent variables and limited collinearity between the independent

\begin{tabular}{lcccccccc}
\hline & \multicolumn{3}{c}{ Job satisfaction } & \multicolumn{3}{c}{ Turnover intention } & \multicolumn{2}{c}{ Popularity } \\
\hline & Model 1 & Model 2 & Model 3 & Model 4 & Model 5 & Model 6 & Model 7 & Model 8 \\
Education background & 0.021 & 0.008 & 0.030 & -0.121 & -0.111 & -0.134 & -0.085 & -0.094 \\
Total compensation & 0.105 & 0.109 & 0.122 & 0.213 & 0.212 & 0.198 & -0.057 & -0.055 \\
Gender & 0.018 & 0.032 & 0.012 & -0.041 & -0.051 & -0.031 & 0.078 & 0.088 \\
\hline
\end{tabular}

variables. Next, we used hierarchical regression analysis to test each of our hypotheses.

Table II. Hierarchical regression analysis of popularity 


\begin{tabular}{|c|c|c|c|c|c|c|c|c|}
\hline Age & $-0.278^{*}$ & $-0.243 *$ & $-0.222 *$ & $-0.288^{*}$ & $-0.316^{* *}$ & $-0.338 * *$ & -0.119 & -0.095 \\
\hline Current promotions & $0.361 * * *$ & $0.297 * * *$ & $0.267 * *$ & -0.124 & -0.075 & -0.042 & $0.178^{*}$ & 0.134 \\
\hline Previous promotions & $0.201 * *$ & $0.149^{*}$ & 0.109 & 0.055 & 0.094 & 0.138 & $0.214 * *$ & $0.178^{*}$ \\
\hline Position tenure & 0.009 & -0.025 & 0.040 & -0.131 & -0.107 & -0.177 & $-0.261 * *$ & $-0.284 * *$ \\
\hline Organizational tenure & -0.093 & -0.067 & -0.129 & 0.141 & 0.121 & 0.189 & $0.255^{*}$ & $0.272 * *$ \\
\hline Tenure with supervisor & -0.012 & -0.005 & -0.003 & $0.248^{*}$ & $0.244^{*}$ & $0.242 *$ & -0.015 & -0.011 \\
\hline Political skills & & $0.270 * * *$ & $0.227 * *$ & & $-0.205 * *$ & $-0.160 *$ & & $0.186^{*}$ \\
\hline Popularity & & & $0.227 * *$ & & & $-.244 * *$ & & \\
\hline $\mathrm{R}^{2}$ & $0.153^{* *}$ & $0.219 * * *$ & $0.261 * *$ & $0.118^{*}$ & $0.156^{* *}$ & $0.204 * *$ & $0.170 * * *$ & $0.202 *$ \\
\hline$\Delta \mathrm{R}^{2}$ & & $0.066 * * *$ & $0.041 * *$ & & $0.038 * *$ & $0.047 * *$ & & $0.031^{*}$ \\
\hline $\mathrm{F}$ & $3.140 * *$ & $4.355 * * *$ & $4.934 * * *$ & $2.286^{*}$ & $2.832 * *$ & $3.532 * * *$ & $3.558 * * *$ & $3.917 * * *$ \\
\hline
\end{tabular}

Notes: $\mathrm{n}=237$. Standardized coefficients are shown; ${ }^{*} \mathrm{p}<.05, * * \mathrm{p}<.01, * * * \mathrm{p}<.001$.

As shown in models 2 and 5 of Table II, political skill is positively correlated with job satisfaction $(\beta=0.270, p<0.001)$ and negatively correlated with turnover intention $(\beta=-0.205, p<0.01)$, after controlling for education background, total compensation, gender, age, current promotions, previous promotions, position tenure, organizational tenure, and tenure with supervisor. Thus, we found support for $\mathrm{H} 1$ and $\mathrm{H} 2$.

In models 3 and 6 of Table II, we add popularity to the regressions and find that popularity has significant relationships with job satisfaction $(\beta=0.227, \mathrm{p}<0.01)$ and turnover intention $(\beta=-0.244$, $\mathrm{p}<0.01)$. In addition, the strength of the relationships between political skill and job satisfaction and between political skill and turnover intention can be seen to be reduced but still significant $(\beta=0.227$, $\mathrm{p}<0.01 ; \beta=-0.160, \mathrm{p}<0.05)$, thus supporting H3 and H4. That is, the positive relationship between political skill and job satisfaction and the negative relationship between political skill and turnover intention are both partially mediated by popularity.

Next, we examined the moderating effects of PA on the relationship between political skill and job satisfaction and NA on the relationship between political skill and turnover intention. As shown in models 3 and 6 of Table III, after adding the interaction terms to the regressions, the interaction between political skill and PA is significantly related to job satisfaction $(\beta=-0.130, p<0.05)$, and similarly, the interaction between political skill and NA is significantly related to turnover intention $(\beta=0.246, p<0.01)$. Therefore, our results indicate that PA and NA have moderating effects on job satisfaction and turnover intention. Figures 2 and 3 show the interaction effects based on our regression analyses. Figure 2 shows that the relationship between political skill and job satisfaction is significant for low PA, that is, improved political skill leads to a significant boost in job satisfaction, thus supporting H5. Figure 3 shows that employees with high NA are more likely to leave the organization when their political skill improves, whereas those with low NA are less likely to leave. Hence, our results support H5 and H6. 
Table III. Hierarchical regression analysis of positive affect and negative affect

\begin{tabular}{|c|c|c|c|c|c|c|}
\hline & \multicolumn{3}{|c|}{ Job satisfaction } & \multicolumn{3}{|c|}{ Turnover intention } \\
\hline & Model 1 & Model 2 & Model 3 & Model 4 & Model 5 & Model 6 \\
\hline Education background & 0.008 & -0.022 & -0.026 & -0.111 & -0.093 & -0.08 \\
\hline Total compensation & 0.109 & 0.048 & 0.035 & 0.212 & 0.217 & 0.198 \\
\hline Gender & 0.032 & -0.004 & -0.011 & -0.051 & -0.038 & -0.037 \\
\hline Age & $-0.243 *$ & -0.182 & -0.184 & $-0.316^{* *}$ & $-0.291 *$ & $-0.306^{* *}$ \\
\hline Current promotions & $0.297 * * *$ & $0.207 * *$ & $0.193 * *$ & -0.075 & -0.049 & -0.03 \\
\hline Previous promotions & $0.149 *$ & 0.09 & 0.105 & 0.094 & 0.126 & $0.153^{*}$ \\
\hline Position tenure & -0.025 & 0.03 & 0.058 & -0.107 & -0.162 & -0.156 \\
\hline Organizational tenure & -0.067 & -0.024 & -0.025 & 0.121 & 0.114 & 0.114 \\
\hline Tenure with supervisor & -0.005 & -0.043 & -0.044 & $0.244^{*}$ & $0.256^{* *}$ & $0.270^{* *}$ \\
\hline Political skills & $0.270^{* * *}$ & 0.117 & 0.122 & $-0.205^{* *}$ & $-0.169 *$ & -0.117 \\
\hline Positive affect & & $0.501^{* * *}$ & $0.511^{* * *}$ & & & \\
\hline Negative affect & & & & & $0.220^{* *}$ & $0.219^{* *}$ \\
\hline Political skills $\times$ Positive affect & & & $-0.130^{*}$ & & & \\
\hline Political skills $\times$ Negative affect & & & & & & $0.246^{* *}$ \\
\hline $\mathrm{R}^{2}$ & $0.219^{* * *}$ & $0.423^{* * *}$ & $0.438^{*}$ & $0.156^{* *}$ & $0.197^{* *}$ & $0.252^{* *}$ \\
\hline$\Delta \mathrm{R}^{2}$ & & $0.203^{* * *}$ & $0.016^{*}$ & & $0.041^{* *}$ & $0.055^{* *}$ \\
\hline $\mathrm{F}$ & $4.355^{* * *}$ & $10.249^{* * *}$ & $9.949^{* * * *}$ & $2.832^{* *}$ & $3.384 * * *$ & $4.235^{* * *}$ \\
\hline
\end{tabular}

Notes: $n=237$. Standardized coefficients are shown; ${ }^{*} p<.05, * * p<.01, * * * p<.001$. 


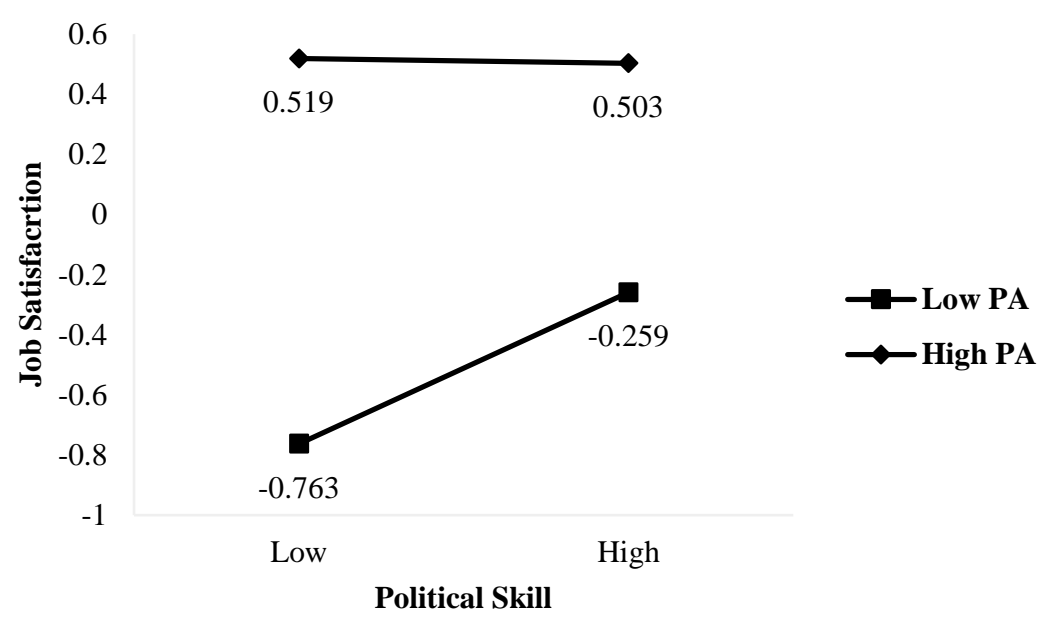

Figure 2. The interactive effect of political skill and positive affect on job satisfaction

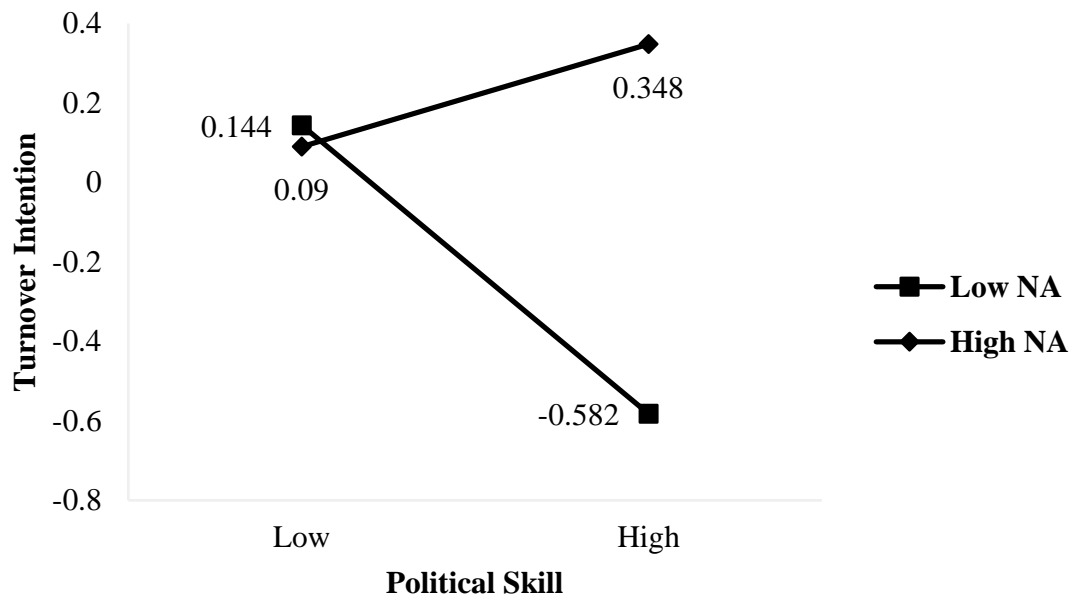

Figure 3. The interactive effect of political skill and negative affect on turnover intention

\section{Discussion}

Political skill is widely recognized to be an essential individual resource that enables employees to secure the valuable resources needed to achieve their tasks and ensure positive outcomes16. However, few studies have examined the underexplored mechanism through which political skill influences job satisfaction and turnover intention. Drawing on the social capital theory, in this study, we developed a theoretical framework to empirically examine the effects of political skill on job satisfaction and turnover intention. In particular, we included employees' popularity as a critical mediator and PA and NA as moderators in our model. By demonstrating how these mediating and moderating mechanisms operate in our framework, our findings clarify the relationships between political skill and job satisfaction and turnover intention through the lens of the conversion of individual resource into social capital.

\subsection{Theoretical Implications}


Our study makes several contributions to the literature. Firstly, the present study emphasizes that popularity is also a powerful explanatory mechanism for the relationship between political skill and job satisfaction and turnover intention. Although political skill has long been considered to have a significant influence on individual work outcomes30, the research on political skill has mainly highlighted its direct or moderating effects on workplace outcomes3940. Drawing on the social capital theory, this study suggests popularity as an internal mechanism and the results confirm that the effects of political skill are transmitted through popularity, which thus provide an enriched theoretical perspective on the indirect mechanisms. Furthermore, the mediating role of popularity suggests that how politically skilled individuals manage to convert their individual resource into social capital, which in turn affects the specific workplace outcomes.

Secondly, we examined the main effect of the acquired resource (i.e. political skill) and the moderating effect of the inherently stable individual resource (i.e. PA/NA) on job satisfaction and turnover intention, which expand the antecedents and the boundary conditions of both job satisfaction and turnover intention through the lens of individual resources. As predicted, the results verify our hypotheses that the effects of political skill is positively related to job satisfaction and negatively related to turnover intention. And our findings indicate that PA and NA have different influence on the relationship between political skill and job satisfaction and turnover intention. When political skill is improved, individuals with high PA tend to experience higher levels of job satisfaction than their low PA counterparts. However, the moderating effect of NA on the relationship between political skill and turnover intention is much more complex. Specifically, individuals with high NA have a stronger turnover intention because the politically skilled are more confident that they will find employment elsewhere, whereas individuals with low NA are less likely to turnover when their political skill improves.

Finally, our study empirically examines the effect of employees' popularity in the context of workplace, which addresses the gap in the fields of organizational behaviors. Besides, the literature on popularity mainly focuses on demographic characteristics and personality traits (i.e. core self-evaluations18; prototypicality, physical attractiveness, and the "Big Five"19), our study further extends the nomological framework of popularity by incorporating political skill as an antecedent and job satisfaction and turnover intention as outcomes. As indicated in our theoretical framework, political skill determines the extent to which individuals achieve popularity among their peers.

\subsection{Practical Implications}

Our findings also offer some practical implications. First, our results indicate that political skill influences individuals' popularity, job satisfaction, and turnover intention. Accordingly, organizations should introduce training to develop their employees' political skills, which can be enhanced through developmental processes (e.g. instruction, experiential exercises, mentoring30). $\mathrm{Li}$, Sun, and Cheng40 proposed that political skills training can generate more politically skilled employees who are able to achieve higher performance. Case studies, role-playing, and communication training are other effective ways to help employees develop their political skills. Employees should also pay attention to improving their own political skills so that they can better adapt to the contingent environment and advance their performance and careers.

Second, as an intervening mechanism, popularity explains why politically skilled employees are associated with both higher job satisfaction and lower turnover intention. The more popular an employee is among his or her coworkers, the higher the job satisfaction and the lower the turnover intention he or she will experience. Thus, supervisors should consider how to motivate their employees to actively improve their interpersonal relationships with their peers and enhance their popularity within the organization. In line with this, human resource supervisors should consider using 360-degree feedback in their performance appraisals to make their employees clearly aware of their shortcomings and prompt them to take the initiative to improve their popularity. 
Third, given the effects of PA and NA on the job satisfaction and turnover intention of politically skilled employees, supervisors should consider developing ways to enhance their employees' emotions and guide them to cultivate positive affect. The research on emotion management41,42 has shown that individuals can improve their ability to manage their emotions through training. Therefore, human resource supervisors should consider developing effective training practices to help their employees develop their emotion management skills and enhance their emotional intelligence.

\subsection{Limitations and Future Research}

The results of this study should be interpreted in the light of several limitations. First, we asked supervisors to evaluate employees' popularity, but this method is not exactly match the definition of popularity. As Bukowski and Hoza25 argued, popularity reflects the general opinion of "the beholders" rather than "the beholder" of the group, future researches are supposed to use ratings of both supervisors and peers.

In addition, the data of the present research were only collected in China. Given the high power distance and the high collectivism in China, the respondents in our study may have influenced the results. Thus, future research should be cautious about the comparison in different cultural contexts when applying the findings in other societies, especially in Western countries.

Another limitation of this study is that political skill, job satisfaction, turnover intention, popularity, PA, and NA were regarded as high-level constructs when we validated the proposed hypotheses. However, it should be noted that these variables are multidimensional. Therefore, an important direction for future research would be to test the effects of the different dimensions.

Finally, we verified the moderating effects of PA on the relationship between political skill and job satisfaction and NA on the relationship between political skill and turnover intention. Future research could expand this work by examining whether PA affects the relationship between political skill and turnover intention and whether NA affects the relationship between political skill and job satisfaction.

Author Contributions: Conceptualization, Y.L. and M.M.; Methodology, Y.L. and M.M.; Software, Y.L. and M.M.; Validation, M.M.; Formal Analysis, M.M.; Investigation, Y.L.; Writing-Original Draft Preparation, M.M.; Writing-Review And Editing, Y.L. and M.M.; Visualization, M.M.; Supervision, Y.L.

Funding:This research received no external funding.

Conflicts of Interest:The authors declare no conflict of interest.

\section{References}

1. Brayfield, A.; Rothe, H. An index of job satisfaction. J. Appl. Psy. 1951, 35, 307-311.

2. Judge, T.A.; Heller, D.; Mount, M.K. Five-factor model of personality and job satisfaction: A meta-analysis. J. Appl. Psy. 2002, 87, 530-541. http://dx.doi.org/10.1037//0021-9010.87.3.530

3. Babalola, M. T.; Stouten, J.; Euwema, M. Frequent change and turnover intention: The moderating role of ethical leadership. J. Bus. Ethics. 2016, 134, 1-12. http://dx.doi.org/10.1007/s10551-014-2433-z

4. Zhang, S.; Liu, Z. A meta-analysis of the relationship between organizational identification and turnover intention. Acta Psychol. China. 2016, 48, 1561. http://dx.doi.org/10.1111/j.1467-6486.2009.00871.x 
5. Templer, K. J. Five-factor model of personality and job satisfaction: The importance of agreeableness in a tight and collectivistic Asian society, Applied Psychology. 2012, 61, 114-129. http://dx.doi.org/10.1111/j.1464-0597.2011.00459.x

6. Park, J. H.; Newman, A.; Zhang, L.; Wu, C.; Hooke, A. Mentoring functions and turnover intention: The mediating role of perceived organizational support. Int. J. Hum. Resour. Manag. 2016, 27, 1173-1191. http://dx.doi.org/10.1080/09585192.2015.1062038

7. Chen, P.; Sparrow, P.; Cooper, C. The relationship between person-organization fit and job satisfaction. J. Manage. Psychol. 2016, 31, 946-959. http://dx.doi.org/10.1108/jmp-08-2014-0236

8. Li, M.; Wang, Z.; Gao, J.; You, X. Proactive personality and job satisfaction: The mediating effects of self-efficacy and work engagement in teachers. Curr. Psychol. 2017, 36, 48-55. http://dx.doi.org/10.1007/s12144-015-9383-1

9. Hobfoll, S. E. Conservation of resources. A new attempt at conceptualizing stress. Am. Psychol. 1989, 44, 513. http://dx.doi.org/ 10.1037/0003-066x.44.3.513

10. Ferris, G. R.; Treadway, D. A.; Kolodinsky, R. W.; Hochwarter, W. A.; Kacmar, C. J.; Douglas, C.; Frink, D. D. Development and validation of the political skill inventory. J. Manage. 2005, 31, 126-52. http://dx.doi.org/10.1177/0149206304271386

11. Lvina, E.; Maher, L. P.; Harris, J. N. Political skill, trust, and efficacy in teams. J. Leadersh. Organ. Stud. 2016, 24, 95-105. http://dx.doi.org/10.1177/1548051816657984

12. Mahajan, A.; Toh, S. M. Group cultural values and political skills: A situationist perspective on interpersonal citizenship behaviors. J. Int. Bus. Stud. 2017, 48, 113-121. http://dx.doi.org/10.1057/s41267-016-0036-x

13. Blickle, G.; Meurs, J. A.; Zettler, I.; Solga, J.; Noethen, D.; Kramer, J., Ferris, G. R. Personality, political skill, and job performance. J. Vocat. Behav. 2008, 72, 377-387. http://dx.doi.org/10.1016/j.jvb.2007.11.008

14. Harris, K. J.; Harris, R. B.; Brouer, R. L. LMX and subordinate political skill: Direct and interactive effects on turnover intentions and job satisfaction. J. Appl. Psy. 2009, 39, 2373-2395. http://dx.doi.org/10.1111/j.1559-1816.2009.00530.x

15. Treadway, D. C.; Breland, J. W.; Williams, L. M.; Cho, J.; Yang, J. Social influence and interpersonal power in organizations: Roles of performance and political skill in two studies. J. Manage. 2013, 39, 1529-1553. http://dx.doi.org/10.1177/0149206311410887

16. Munyon, T. P.; Summers, J. K.; Thompson, K. M.; Ferris, G. R. Political skill and work outcomes: A theoretical extension, meta-analytic investigation, and agenda for the future. Pers. Psychol. 2015, 68, 143-184. http://dx.doi.org/10.1111/peps.12066

17. Kimura, T. A review of political skill: Current research trend and directions for future research. Int. J. Manag. Rev. 2015, 17, 312-332. http://dx.doi.org/10.1111/ijmr.12041

18. Scott, B. A.; Judge, T. A. The popularity contest at work: Who wins, why, and what do they receive?. J. Appl. Psy. 2009, 94, 20-33. http://dx.doi.org/10.1037/a0012951 
19. Scott, B. A. A conceptual framework for the study of popularity in the workplace. Organ. Psychol. Rev. 2013, 3, 161-186. http://dx.doi.org/10.1177/2041386612464092

20. Wright, T. A.; Cropanzano, R. Emotional exhaustion as a predictor of job performance and voluntary turnover. J. Appl. Psy. 1998, 83, 486-93. http://dx.doi.org/10.1037/0021-9010.83.3.486

21. Coleman, J. S. Social capital in the creation of human capital. Am. J. Sociol. 1988, 94, 95-120. http://dx.doi.org/10.1086/228943

22. Pfeffer, J. Power in organizations. J. Policy. Anal. Manag. 1982, 2, 307-8; author reply, 308. http://dx.doi.org/10.2307/3324486

23. Mintzberg, H. Power in and around organizations. Am. J. Sociol. 1983, 30, 1-23

24. Rubin, K. H.; Bukowski, W.; Parker, J. G. Peer interactions, relationships, and groups. In W. Damon and R. M. Lerner and N. Eisenberg, Ed. Dev. Psychol. New York, NY, 2006, 571-645.

25. Bukowski, W. M. and Hoza, B. Popularity and friendship: Issues in theory, measurement, and outcome. In T. Berndt; G. W. Ladd, Ed. Peer relationships in child development. New York, NY, 1989, 15-45.

26. Cullen, K. L.; Fan, J.; Liu, C. Employee popularity mediates the relationship between political skill and workplace interpersonal mistreatment. J. Manage. 2014, 40, 1760-1778.

http://dx.doi.org/10.1177/0149206311435104

27. Adler, P. S.Social capital: Prospects for a new concept. Acad. Manag. Rev. 2002, 27, 17-40. http://dx.doi.org/10.5465/amr-2002-5922314

28. Seibert, S. E.; Kraimer, M. L.; Liden, R. C. A social capital theory of career success. Acad. Manage. J. 2001, 44, 219-237. http://dx.doi.org/ 10.2307/3069452

29. Perrewé, P. L.; Zellars, K. L.; Rossi, A. M.; Kacmar, C. J.; Ralston, D. A. Neutralizing job stressors: Political skill as an antidote to the dysfunctional consequences of role conflict. Acad. Manage. J. 2004, 47, 141-52. http://dx.doi.org/10.2307/20159566

30. Ferris, G. R.; Treadway, D. C.; Perrewe, P. L.; Brouer, R. L.; Douglas, C.; Lux, S. Political skill in organizations. J. Manage. 2007, 33, 290-320. http://dx.doi.org/10.1177/0149206307300813

31. Ferris, G. R.; Berkson, H. M.; Kaplan, D. M.; Gilmore, D. C.; Buckley, M. R.; Hochwarter, W. A.; Witt, L. A. 1999. Development and initial validation of the political skill inventory. In Proceedings of the 59th AOM Annual National Meeting, Chicago, America, 1999, Aug 09-13.

32. Li, Y. Does popularity at work matter? Examining the effects on career satisfaction through self-evaluation and abilities. Soc. Behav. Personal. 2016, 44, 1601-1612. http://dx.doi.org/10.2224/sbp.2016.44.10.1601

33. Joel Koopman; Fadel K. Matta; Brent A. Scott; Donald E. Conlon. Ingratiation and popularity as antecedents of justice: A social exchange and social capital perspective. Organ. Behav. Hum. Dec. 2015, 131, 132-148. http://dx.doi.org/10.1016/j.obhdp.2015.09.001 
34. Watson, D.; Clark, L.; Tellegen, A. Development and validation of brief measures of positive and negative affect: The PANAS Scale, J. Pers. Soc. Psychol. 1988, 54, 1063-1070. http://dx.doi.org/10.1037/0022-3514.54.6.1063

35. Extremera, N.; Rey, L. Ability emotional intelligence and life satisfaction: Positive and negative affect as mediators. Pers. Indiv. Differ. 2016, 102, 98-101. http://dx.doi.org/10.1016/j.paid.2016.06.051

36. Wei, L. Q.; Liu, J.; Chen, Y.; Wu, L. Z. Political skill, supervisor-subordinate guanxi and career development of subordinates: Evidence from Chinese firms. J. Manage. Stud. 2010, 47, 437-54. http://dx.doi.org/10.1111/j.1467-6486.2009.00871.x

37. Mobley, William H. Intermediate linkages in the relationship between job satisfaction and employee turnover. J. Appl. Psy. 1977, 62, 237-240. http://dx.doi.org/10.1177/0149206309359810

38. Epitropaki, O.; Kapoutsis, I.; Ellen, B. P.; Ferris, G. R.; Drivas, K.; Ntotsi, A. Navigating uneven terrain: The roles of political skill and LMX differentiation in prediction of work relationship quality and work outcomes. J. Organ. Behav. 2016, 37, 1078-1103. http://dx.doi.org/10.1002/job.2100

39. Ahearn, K. K.; Ferris, G. R.; Hochwarter, W. A.; Douglas, C.; Ammeter, A. P. Leader political skill and team performance. J. Manage. 2004, 30, 309-327. http://dx.doi.org/10.1016/j.jm.2003.01.004

40. Li, J., Sun, G.; Cheng, Z. The influence of political skill on salespersons' work outcomes: A resource perspective. J. Bus. Ethics. 2017, 141, 551-562. http://dx.doi.org/10.1007/s10551-015-2696-z

41. Bolton, S. C. 2005. Emotion management in the workplace, England: Macmillan.

42. Kluemper, D. H.; Degroot, T.; Choi, S. Emotion management ability predicting task performance, citizenship, and deviance. J. Manage. 2013, 39, 878-905. http://dx.doi.org/10.1177/0149206311407326 